\title{
Ciências sociais e representações: estudo dos fenômenos representativos e processos sociais, do local ao global*
}

Denise Jodelet**

Resumo: O objetivo deste artigo é examinar a contribuição que uma abordagem desenvolvida na psicologia social - o estudo das representações sociais - pode trazer às ciências sociais. Como ponto de partida, a reflexão se apoia na constatação do novo interesse desenvolvido nas ciências sociais pelas relações entre o saber ordinário e o saber erudito, a inscrição social dos processos cognitivos, a importância da noção de "comum", as necessidades de reconfigurar as relações entre disciplinas e considerar a complexidade dos fenômenos abordados. Um exame do tratamento da noção de representação social e/ou coletiva na história das ciências sociais - notadamente na antropologia, na história e na sociologia - recai sobre as reconhecidas propriedades dos fenômenos representativos e sobre seus papéis na vida social. Os eixos de problematização de seu estudo são apresentados em um quadro que resume o espaço de pesquisa que os concerne. Depois de discutir as críticas científicas e políticas dirigidas ao "representacionalismo", um esquema que coloca fenômenos representativos na interseção de três esferas de pertencimento - subjetiva, intersubjetiva e trans-subjetiva - e permite mostrar a pertinência do estudo das representações sociais em um espaço globalizado. Essa pertinência é ilustrada pelo exemplo de trabalhos relativos aos efeitos dos vetores da globalização sobre identidades sociais locais, e pelas posições adotadas pelos pesquisadores latino-americanos em face da importação de modelos emprestados dos círculos dominantes do Primeiro Mundo.

Palavras-chave: Representações coletivas. Conhecimento ordinário. Fenômenos representativos. Processos sociais.

\section{Social sciences and representations: a study of representative phenomena and social processes, from local to global}

abstract: The purpose of this article is to examine the potential contribution that the study of representations - an approach developed in the field of social psychology - can bring to the social sciences. At the outset, the discussion is based on the observation of the social sciences' emerging interest in the relation between ordinary and scholarly knowledge, the social inscription of cognitive processes, the importance of the notion of "common", the need to reconfigure the relationship among disciplines, and that of considering the complexity of phenomena when addressing them. The examination of the notion of social and/or collective representation within the history of the social sciences, notably in Anthropology, History and Sociology, falls on the recognized properties of representative phenomena and on their roles in social life. The lines of problematization of this study are presented in a table summarizing the research space that concerns them. After discussing the scientific and political critiques of 'representationalism', a

\author{
* Tradução: José \\ Geraldo de Oliveira \\ Almeida. \\ ** Denise Jodelet \\ foi diretora de \\ estudos da École \\ des Hautes Études \\ en Sciences Sociales \\ (Ehess), Paris, \\ França, aposentada, \\ é presidente da \\ Rede Mundial \\ Serge Moscovici / \\ Fondation Maison \\ des Sciences de \\ I'Homme. \\ <denise.jodelet@ \\ ehess.fr>.
}


scheme that places representative phenomena at the intersection of three spheres: subjective, intersubjective, and transsubjective allows us to show the pertinence of the study of social representations in a globalized space. This pertinence is illustrated by works dealing with the effects of globalization vectors on local social identities, and by the positions adopted by Latin American researchers regarding the importation of models borrowed from the dominant circles of the first world.

Keywords: Collective Representations. Ordinary Knowledge. Representative Phenomena. Social processes.

$\square$ ste texto apresenta uma perspectiva que, apesar de fazer parte da psicologia social, tem uma nítida relevância para todas as ciências sociais, no atual contexto da reflexão epistemológica. A seguir, após identificar o porquê das reivindicações por um lugar de estudo das representações sociais e dos fenômenos representativos no âmbito das ciências sociais, o texto irá pontuar os aportes que tais estudos podem trazer para as abordagens dos processos sociais, tanto numa escala local como global. Esta reflexão se apoia, principalmente, nos trabalhos realizados na França, onde o uso da noção de representação teve uma história longa e agitada, ainda que faça também referência às contribuições elaboradas em outros países para abordar as questões que o fenômeno da globalização coloca para as culturas locais.

\section{Sobre o surgimento do conceito de representação no espaço científico}

Os recentes desenvolvimentos científicos colocam em destaque os questionamentos e as proposições sobre o pensamento social e os fenômenos representativos. Várias e distintas correntes contribuem para isso.

Do ponto de vista epistemológico, o surgimento das ciências cognitivas desencadeou, no seio da sociologia e da filosofia social, uma nova preocupação em defesa do caráter social do pensamento. Duas obras coletivas publicadas nessa década atestam isso. Uma, intitulada Le mental et le social (Amboise \& Chauviré, 2013), empenha-se em demonstrar a natureza social do pensamento. Mais recentemente, La distinction des savoirs (Walliser, 2015) reúne pensadores de diversas disciplinas para refletir sobre a relação entre o conhecimento ordinário - também chamado de comum - e o conhecimento erudito. Essas obras, não fazem explicitamente nenhuma referência à corrente de estudo das representações sociais, a mencionando apenas de forma alusiva. No entanto, os autores abordam os problemas que envolvem os estudos das representações sociais de forma relativamente tímida, como evidenciado na introdução do segundo livro, ao anunciarem que "os textos a se- 
guir se contentarão com uma abordagem impressionista do conhecimento comum" (Walliser, 2015: 11).

Assim, a atual reflexão epistemológica opõe a uma "teoria mental do social" - que explica as interações sociais a partir do conhecimento obtido sobre as habilidades cognitivas e práticas dos indivíduos -, uma "teoria social do mental", a explicar os processos cognitivos e práticos por seus "encaixes em seus contextos sociais". Voltarei a esta questão depois de mostrar que o estudo das representações sociais e/ou coletivas sempre procurou superar essa dicotomia.

Hoje, os pensadores do político vêm juntar suas vozes ao renascimento da reflexão sobre a base social das formas de pensar, ver, sentir, agir e sobre a importância do conhecimento ordinário no trabalho sociológico, que serve de apoio para o desenvolvimento de um saber sobre a vida social e remete às competências dos atores ou ainda às relações do público com o conhecimento erudito, por meio da inscrição deste último em dispositivos institucionais e materiais (Steiner, 2015). Essa nova corrente de interesse pelo pensamento social, que se torna uma "arma" contra os males sociais (de Lagasnerie, 2017), é expressa por meio da utilização da noção de "comum". Essa noção, de conotação contestatória em relação à ordem social, aplica-se seja ao que é importante para o público (Laugier, 2013), seja às formas de sensibilidade compartilhadas (Rancière, 2012), seja ainda à atividade dos homens que conduz a um uso comum de certos recursos que são objeto de utilização privada ou pública (Dardot \& Laval, 2014).

Essa renovação do interesse pelas dimensões ideais do social é reforçada pela evolução das orientações da pesquisa em ciências sociais, levando a uma visão um tanto "ecumênica", de sua prática. De fato, as mutações observadas nas ciências sociais e humanas, nos últimos 40 anos, resultaram numa reconfiguração da relação entre as disciplinas (Wieviorka, 2007). Haveria um declínio das especializações ou da pretensão de domínio de determinadas disciplinas, com a ascensão das múltiplas relações que operam com base no "empréstimo", na "infusão", na "colaboração" e na "coordenação" em torno de novos temas, quando a noção de sujeito passa a ocupar um lugar central. Nessa perspectiva, os fenômenos de representação a que se referem as diferentes ciências humanas revelam-se como um espaço de encontro privilegiado entre as ciências sociais, a psicologia, a psicanálise, as ciências cognitivas e a filosofia.

Esse caráter transversal das representações sociais se coaduna com a perspectiva transdisciplinar (Jodelet, 2016), que reivindica a complexidade dos fenômenos focados pelas ciências sociais, tal como indicado por Edgar Morin: 
Há concepções científicas que mantêm sua vitalidade porque se recusam a um enclausuramento disciplinar. Gostaria de enfatizar a surpreendente variedade de circunstâncias que fazem avançar as ciências, quebrando o isolamento das disciplinas, seja através da circulação de conceitos ou de esquemas cognitivos, seja por interferências e intromissões, seja por aumento de complexidade de disciplinas em campos de múltiplas competências, seja pelo surgimento de novos esquemas cognitivos e novas hipóteses explicativas, seja, finalmente, pela constituição de concepções organizadoras que permitem articular áreas disciplinares em um campo teórico comum. Hoje, creio que devemos tomar consciência deste aspecto que é o menos esclarecido na história oficial das ciências e que é um pouco como a face obscura da lua. As disciplinas são totalmente justificadas intelectualmente desde de que mantenham um campo de visão que reconheça e conceba a existência de laços e de solidariedades. Além disso, elas são totalmente justificadas apenas se não ocultarem as realidades globais. Por exemplo, a noção de homem está fragmentada entre diferentes disciplinas biológicas e todas as disciplinas das ciências humanas: uma estuda a psique, outra o cérebro, outra o organismo, os genes, a cultura etc. Trata-se, de fato, de múltiplos aspectos de uma realidade comple$x a$, mas que só fazem sentido se forem relacionados a essa realidade complexa, em vez de ignorá-la (Morin, 1995).

Diante dessa complexidade e da exigência de inter-relações, a noção de representação, que permeia todas as disciplinas, aparece como mediação incontornável para proporcionar uma visão global do que seja o homem e seu mundo de objetos. A esse respeito, o modelo de representações sociais, proposto desde 1961 na obra seminal de Moscovici (1974) - A psicanálise, sua imagem e seu público - e desenvolvido, desde então, em uma vasta literatura, é oferecido como elemento de articulação entre a psicologia social e as ciências vizinhas. Somente o estudo dos processos e dos produtos, pelos quais os indivíduos e os grupos constroem e interpretam "seu mundo de vida", permite a integração da subjetividade com as dimensões social, cultural e histórica.

\section{A representação nas ciências sociais}

Abordaremos, em seguida, o que emerge do exame da forma como as ciências sociais têm considerado as representações sociais e coletivas. Na curta história das ciências sociais, encontramos a noção de representação desde sua origem, em seus fundadores - Marx, Durkheim, Lévy-Bruhl - que Ihe atribuíram conteúdos. Sob a denominação de "representação coletiva", goza de um status central na abordagem da vida social. Em Marx, recebe uma acepção original enquanto ilusão, "sistematização distorcida e mistificada da realidade", mas agindo como força material objetiva. 
Essa concepção inspirou as chamadas "teorias da suspeita", alguns a considerando seja como forma de ignorância, seja como forma de legitimação, de justificação das práticas ou ainda como meio de acesso à ideologia, instância inapreensível.

Durkheim (1967) designa como representações coletivas o conjunto das "produções mentais sociais" que são as religiões, os mitos, as ciências, as categorias de apreensão do tempo e do espaço, e até mesmo as formas correntes de pensamento e saber. Ainda que comparáveis às representações individuais, uma vez que obedecem a "leis abstratas comuns", as representações coletivas são diferentes de acordo com dois critérios. Por um lado, a estabilidade conferida pela transmissão, reprodução e memória coletiva e, por outro, a seleção de seus objetos que devem ter "uma certa gravidade" para "afetar a base mental da sociedade". As representações são as obras de uma comunidade que as compartilha, as reproduz e se expressa por meio delas: "O que as representações coletivas traduzem é a forma pela qual o grupo pensa a si próprio em suas relações com os objetos que o afetam". Essa dimensão identitária será retomada nas abordagens mais recentes das representações coletivas.

Com a noção de mentalidade, Lévy-Bruhl vai atenuar o caráter racional que Durkheim dá à representação coletiva, introduzindo a noção de participação, cuja presença ou ausência caracteriza de maneira distinta sistemas culturais e sociais situados em tempos e espaços diversos.

Weber, por sua vez, contribuirá para o refinamento da abordagem do conhecimento social com a distinção das racionalidades que são implementadas na ação: a ação racional instrumental, mobilizando uma grande carga cognitiva e um conjunto de conhecimentos, bem como uma racionalidade axiológica; a ação tradicional, baseada na transmissão social e ação afetiva, marcada pela subjetividade e pela emoção.

O interesse das ciências sociais pelas representações, no entanto, passou por um período de eclipse, para renovar-se, a partir dos anos 1970-1980, após conturbações relacionadas a fatores históricos e epistemológicos. O fim das "grandes narrativas", que anunciavam o progresso humano e o fim da história, foi seguido, após o colapso do império soviético, pelo abandono do que foi chamado "pensamento russo" ou "pensamento chinês", enquanto emergiam novas correntes de pensamento relacionadas à condição pós-moderna. A consequência foi uma reabilitação do conceito de representação, acompanhada por um retorno à ideia de sujeito ativo e pensante e por uma nova interrogação quanto ao vínculo social.

Como indiquei durante a Jornada Internacional sobre Representações Sociais, realizada em 2007, na Universidade de Brasília (Jodelet, 2009), posteriormente desen- 
* Traduzido do francês co-naissance, jogo de palavras retomado de Godelier pela autora que significa tanto conhecimento (connaissance) como nascimento mútuo (co-naissance) (n. do t.). volvida em uma nova publicação (Jodelet, 2017) - Representações sociais e mundos de vida -, o conceito de "representação" será encontrado em todas as definições de fenômenos que emergem no campo das ideias. Seu tratamento é objeto de uso explícito e racional nas ciências sociais. Elas encontram neste conceito um meio de acesso às dimensões simbólicas, culturais e práticas dos fenômenos sociais, bem como um instrumento que permite pensar a relação do mental e do material como meio para dar lugar novamente à cultura e ao reconhecimento de que os fatos sociais são objetos de conhecimento. Essas correntes consideram as representações como operadores simbólicos e lógicos da vida social, cada um privilegiando um momento particular de sua intervenção: a antropologia, no momento da constituição da sociedade; a sociologia, nas transformações sociais; a história, no jogo temporal das formas sociais, em durações mais ou menos prolongadas.

Na antropologia, a noção de representação permite, para uma primeira corrente, identificar como os processos simbólicos contribuem para a instauração e a manutenção da organização das relações sociais, no seio de uma determinada sociedade. As representações que se estabelecem em uma relação de "conascimento" * com a realidade social têm um caráter significante e instituinte em relação ao real-material, social, ideal, mítico, prático. Outra tendência leva em consideração aportes das ciências cognitivas (Descola, 2006) e estabelece que a maneira de estruturar a experiência do mundo e do outro se dá segundo as modalidades cognitivas universais, cujos arranjos variam de acordo com as culturas e as necessidades das situações concretas.

Na sociologia, vamos trabalhar as representações enquanto concepções que incidem sobre o curso da vida social e o campo da política. As representações intervêm na ação sobre mundo social, na medida em que essa ação se apoia no conhecimento que os atores sociais têm deste mundo e de sua própria posição. As representações orientam suas decisões (Touraine, 2007) e têm o poder de revelar, construir e instituir uma realidade (Bourdieu, 1982). Para outros autores (Faye, 1973; Windisch, 1982), elas permitem, por meio dos discursos, a influência implacável de grupos minoritários ou mesmo sectários (por exemplo, seitas nazistas ou xenófobas na Suíça).

Na história, observamos a passagem da noção de mentalidade para aquela de representação. A partir dos anos 1980, uma divisão se estabelece na história das mentalidades que irá desenhar territórios distintos para o estudo das representações. Por um lado, uma corrente retoma a história das sensibilidades e das emoções que é intimamente associada a um estudo das práticas e das representações que Ihes são subjacentes (Corbin et alii, 2005). Outras correntes - ditas de mi- 
cro-história - centram a história social, política e cultural sobre o universo das representações que, solidárias às situações nas quais são ativadas, servem de mediações simbólicas que contribuem para a instauração dos laços sociais. Atribui-se às representações a função de exprimir três modalidades da relação com o mundo social: a construção da realidade, a expressão da identidade social e, sob a forma institucionalizada, a manutenção da existência de grupos sociais (Chartier, 1989; Lepetit, 1995).

Entre as outras contribuições, na mesma direção, vale mencionar a história cultural cujo objeto é, de acordo com Jean-Pierre Rioux e Jean-François Sirinelli,

\begin{abstract}
o estudo das formas de representação do mundo no seio de um grupamento humano, cuja natureza pode variar - nacional ou regionalmente, social ou politicamente - e a análise de sua gestação, expressão e transmissão. Como os grupos humanos representam e como concebem o mundo ao seu redor? Um mundo figurado ou sublimado - pelas artes plásticas ou pela literatura -, mas também um mundo codificado - pelos valores, o papel do trabalho e do lazer, pela relação com os outros -, contornado - pelo entretenimento -, pensado - pelas grandes construções intelectuais -, explicado - pela ciência -, e parcialmente dominado - pelas técnicas -, dotado de sentido - pelas crenças e sistemas religiosos ou profanos, ou mesmo pelos mitos-, um mundo legado, finalmente, por transmissões devido ao meio, à educação e à instrução (Rioux \& Sirinelli, 1997: 16).
\end{abstract}

\title{
Propriedades reconhecidas das representações sociais ou coletivas
}

As propriedades aqui referidas remetem a um uso - que se tornou recorrente - da noção de representação que revela seu potencial de recursos para o diálogo e para a colaboração entre disciplinas, o que se mostra, atualmente, necessário no que concerne a diversos objetos, temas, áreas de conhecimento. Em particular, o modo de estudar as representações sociais, tal como foi elaborado na tradição da pesquisa em psicologia social, mostra-se em concordância com as perspectivas adotadas nas ciências sociais em razão das seguintes propriedades que a comunidade científica considera como adquiridas. A saber, as representações sociais:

a concernem ao conhecimento dito de senso comum, utilizado na experiência cotidiana;

a são programas de percepção, constructos com status de teoria ingênua, servindo de guia de ação e de leitura da realidade; 
- são sistemas de significações, permitindo interpretar o curso dos acontecimentos e das relações sociais;

- expressam a relação que os indivíduos e os grupos mantêm com seu "mundo de vida" e os outros atores sociais;

u são forjadas na interação e em contato com os discursos em circulação no espaço público; e

- estão inscritas na linguagem e nas práticas e funcionam como linguagem em razão de sua função simbólica e dos referentes que elas fornecem para codificar e categorizar o que povoa o universo de vida.

Ao se considerar essas características - que são consensuais - é possível admitir que as representações façam parte desses "instrumentos mentais", dos quais nos falam os historiadores, e que possam ser ordenados na classe das "mediações simbólicas" de que fala Vygotsky (1984). As questões que se colocam, então, concernem não apenas às modalidades de elaboração dessas produções mentais sociais, mas também à forma pela qual elas intervêm na linguagem e nas práticas sociais para gerar efeitos sociais.

O historiador Charles Morazé (1994) mostrou - no que concerne às relações entre história e saber - que os modelos de abordagem da realidade se transformaram com o tempo, em função do estado dos conhecimentos científicos. No pensamento antigo, e até no Renascimento, a atenção se voltava para as "coisas", o cartesianismo colocou a noção de "fato" no centro do saber até o século XIX, a qual foi substituída pela noção de "força" pelos recentes desenvolvimentos científicos. A forma de abordar as representações ecoa essa centralização na ideia dinâmica de força social. É por esta razão que pessoalmente prefiro me remeter aos "fenômenos representativos" que agem na vida social em vez de uma noção puramente intelectual de representação.

\section{Sobre os fenômenos representativos}

Este deslocamento na direção dos fenômenos representativos apresenta várias vantagens. Ele permite se vincular àquilo que é observável ou às construções intelectuais identificadas pela análise textual de enunciados públicos, de documentos publicados ou registrados durante investigações, sem precisar optar por uma das numerosas definições da noção de representação (retomá-las exigiria muito tempo), nem se fechar numa definição substancial da noção de representação social (o que traria um risco de restringir o olhar dirigido sobre as realidades estudadas). Estes fenômenos permitem identificar, nos materiais inscritos nos contextos de produ- 
ção e de uso concretos, as propriedades formais das representações e os processos de sua formação, seu funcionamento e seus efeitos sociais, tal como representado no Quadro 1.

Este quadro apresenta o campo de estudo das representações sociais e seus grandes eixos de problematização. Indica que as representações, enquanto forma de saber prático, implicam uma relação indissociável entre um sujeito e um objeto. O sujeito é sempre social por sua inscrição no espaço das relações sociais e das comunicações, bem como por seus laços com o outro. Pode-se tratar de um indivíduo ou de um coletivo, a partir de um ponto de vista epistêmico, psicológico ou pragmático. O objeto pode ser humano (um ou mais atores sociais), ou social (um grupo ou um coletivo, ou um fenômeno concernente à vida pública ou privada), ele pode também pertencer ao universo material ou ideal. No que concerne ao objeto, a representação está em uma relação de simbolização (ela ocupa o lugar do objeto) ou de interpretação (ela dá significação ao objeto). No que concerne ao sujeito, a representação tem uma função expressiva e é o produto de uma construção.

Três eixos de problematização podem ser identificados:

À esquerda, encontra-se o eixo que diz respeito às condições de produção e de circulação das representações, referente

- à cultura (seus valores, normas, modelos de pensamento e ação, invariantes);

口 à linguagem e à comunicação interindividual, institucional e midiática;

口 à sociedade da qual ela deriva pelo compartilhamento e vínculo social, e que a determina pelo contexto ideológico e histórico; à inscrição social do sujeito, ou seja, sua posição, seu lugar e sua afiliação; às restrições do tipo de organização no bojo da qual a atividade do sujeito se realiza.

No centro, situa-se o eixo do estudo dos processos e estados das representações, no qual se

a considera os meios de sua manifestação: linguístico, icônico, comportamental etc.;

- examina seu conteúdo e sua estruturação, seus processos de formação e sua lógica; 


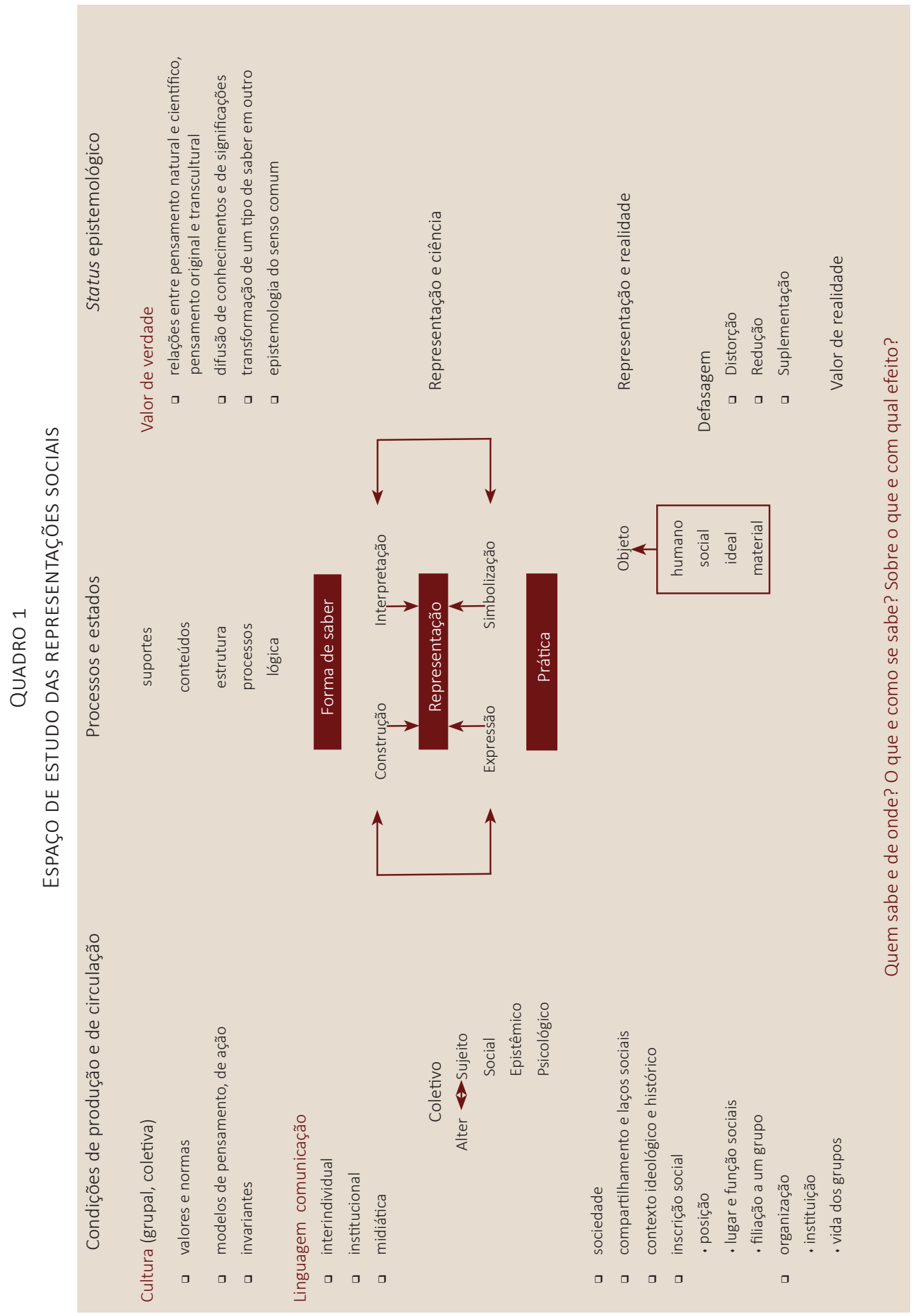


๑ analisa sua base experiencial, suas funções e sua eficácia.

À direita encontra-se o eixo que remete ao status epistemológico das representações, com

a de um lado, o que se refere a seu valor de verdade e que incita um confronto com a ciência: as relações entre pensamento natural e conhecimento científico; os efeitos da difusão dos conhecimentos e dos significados; a transformação e o encontro dos saberes; a epistemologia do senso comum;

- de outro, o que se refere ao seu valor de realidade, isto é, as relações da representação e seus objetos. Ao se considerar que a representação não é uma cópia da realidade, se introduz a ideia de um deslocamento em relação ao objeto representado, seja uma distorção de seus elementos, seja uma retirada ou uma adição de suas propriedades ou significados. O conjunto dessas questões pode ser resumido na seguinte pergunta: Quem sabe ou quem fala e de onde? O que e como se sabe ou se fala? Sobre o que e com qual efeito?

Ademais, falar de fenômenos representativos autoriza não restringir a qualificação das representações por uma escolha drástica entre os qualificativos de "social" e "coletivo". Serge Moscovici argumentou amplamente sua escolha pelo qualificativo "social", dando duas razões fundamentais: evitar o caráter restritivo que reveste, em Durkheim, a referência ao coletivo; dar conta da formação específica das representações pelo viés da comunicação social. Mas, deve-se ter em mente que, em sua diversidade, os fenômenos representativos, mesmo resultando da comunicação social, podem apresentar formas que são coletivas, no seio de um grupo ou de uma cultura, e podem ser endossados subjetivamente. Essas características se tornaram proeminentes pelas consequências do processo de globalização, o qual retomarei na sequência. Ademais, sobre os recentes modelos do "comum" e de seu compartilhamento, repousa a questão do caráter "coletivo" das formas de pensar, sentir e agir. Isso convida a manter, em alguns casos, o uso de representações coletivas.

Recorrer à expressão "fenômenos representativos" também permite dar conta da diversidade das formas pelas quais as representações sociais se manifestam. Pois, mesmo que se estabeleça uma estreita relação das representações sociais com a linguagem e o discurso, mesmo que sejam tratados como prática ou força material, não constituem a única prática social a levar em consideração a abordagem da construção social dos conhecimentos e significados relativos às realidades cotidianas, bem como dos efeitos relacionados à ordem dos saberes de senso comum. 
De fato, existem diferentes formas de expressão de como um sujeito social (indivíduo, grupo ou coletivo) vê ou dá a ver o seu mundo, e como os objetos, estados das coisas, acontecimentos e personagens constituem esse mundo. Pode ser por meio de manifestações não apenas verbais, discursivas, mas também icônicas, comportamentais, gestuais, rituais, rotineiras, práticas ou ainda artísticas. Todas respondem, então, a códigos de agir instituídos por um quadro de atividade produtiva ou de intervenção sobre o ambiente, ou ainda institucionalizados por medidas políticas, legais ou administrativas etc. Para dar apenas um exemplo, em um estudo das representações da loucura em uma comunidade rural, onde os pacientes que sofrem de transtornos psíquicos foram alojados nas casas dos moradores desta comunidade (Jodelet, 2005), as práticas reservadas ao cuidado de seus corpos e de seus pertences pessoais revelaram a existência de uma crença de contágio da loucura por meio do contato com fluidos corporais, baseado em antiga representação do funcionamento corporal e mental. Essa crença permitiu que fosse assegurado o afastamento social dos doentes.

\section{Sobre o debate em torno do representacionalismo}

A diversidade das formas da representação também é evidenciada a partir do próprio tratamento do que é chamado de "a crise da representação". Foi desenvolvida inicialmente a respeito da representação literária, artística e política, antes de ser retomada sob o efeito da mudança de paradigma nas ciências humanas introduzida pelo linguistic turn e pela crítica pós-moderna do modelo positivista.

Porém, mais recentemente, o campo da exploração das representações foi restringido por causa de seu foco sobre o aspecto puramente mental. Critica-se o "representacionismo neocartesiano persistente na filosofia do espírito cognitivista contemporâneo" porque ele corresponderia a uma visão intrassubjetiva dos fenômenos representativos. A reflexão sobre a formação dos conhecimentos ordinários, no quadro sociológico, busca então "recursos conceituais pertinentes" nas perspectivas inspiradas de Wittgenstein, Dewey e Mead que propõem "uma firme tradição pragmática fazendo da linguagem e do pensamento - concebidos em termos de interação - uma arte social" (Amboise \& Chauviré, 2013: 10). Mas, embora privilegiando o caráter social da troca verbal e discursiva, esta posição esquece as modalidades de encarnação das ideias nos corpos, nos comportamentos e nas obras que são fenômenos atuando na vida e nas relações sociais.

Ademais, deve-se enfatizar que os críticos pós-modernos postulam que existe, para os defensores da representação, uma identificação desta última com um re- 
flexo, uma cópia do real. O que não foi o caso de nenhum dos teóricos franceses ou alemães da representação, e que se encontra em total contradição com os postulados da teoria das representações sociais como construção da realidade. Além disso, essa crítica é de ordem epistemológica: a crise das representações afeta as representações do saber erudito e suas pretensões à verdade. Mas ela não poderia se aplicar ao conhecimento do senso comum, sobre o qual se ocupa o paradigma das representações sociais. Esse saber de senso comum visa a uma "verdade fiduciária", baseada na confiança, o oposto da "verdade legal" da ciência (Moscovici, 2013: 215).

Outra observação diz respeito às razões políticas da crítica à representação. Essa foi dirigida principalmente à antropologia, considerada como se estivesse a reboque, para não dizer cúmplice, do colonialismo. Mas nessa disciplina, a reintrodução do estudo de representações coletivas correspondeu a uma inversão de perspectiva. A palavra foi dada, daí em diante, aos parceiros das pesquisas para que expressassem o sentido de suas práticas, que no passado se contentava em gravar, por meio de uma espécie de "extração de minério", como foi definido pelo antropólogo Olivier de Sardan (1995). Tal perspectiva, amplamente defendida na corrente antropológica francesa, vem também contestar as críticas do período conhecido como "pós-pós-moderno", que começou nos anos 1990, com referência à "dupla crise da representação", e questionando a legitimidade dos pesquisadores e sua capacidade de explicar as experiências de seus parceiros pela restituição textual que dão de sua experiência de campo.

A esse respeito, o uso da expressão "fenômenos representativos" permite escapar desses debates intermináveis, tratando de objetivações concretas das representações. Oferece também a vantagem de respeitar o duplo status das representações sociais e/ou coletivas de ser ao mesmo tempo conhecimentos do mundo de vida e dos sistemas de interpretação deste mundo. O que levanta uma importante questão teórica: como articular conhecimento e significado dando aos objetos representados seu status de saber. De fato, os componentes das representações podem ser classificados nas categorias claramente diferenciadas de saber/significado/sentido. Cada representação, seja de um objeto, uma pessoa ou um acontecimento, compreende vários elementos. Conhecimentos, adquiridos por meio de transmissão ou experiência, significados atribuídos ao objeto de acordo com pressupostos socialmente compartilhados pela comunicação e transmitidos pela linguagem, como expresso por Benveniste (1974), sentidos que adquire para o sujeito, como afirma Vygotski (1984), dependendo de sua compleição psicológica, suas experiências, crenças ou afiliações ideológicas. 
A questão da construção do sentido e do significado é uma problemática central no estudo das representações sociais. Ela se tornou, ao longo das últimas décadas, uma preocupação compartilhada por todas as ciências humanas. Vemos, então, a sociologia preconizar o tratamento dos

fatos sociais como significados, ou seja, acontecimentos singulares que dependem dos elementos conceituais depositados em nosso senso comum e pelos quais se tornam compreensíveis (Noiriel, 1989).

Essa perspectiva ecoa como réplica, nas ciências sociais, da ideia de um sujeito ativo e pensante e de uma nova pergunta sobre os laços sociais. De acordo com François Dosse, isso

implica outra escala de análise, mais próxima dos atores sociais. No cotidiano, as representações desempenham o papel de alavancas metodológicas que permitem interessar-se mais pelo instituinte do que pelo instituído. As noções de situação, momento, geração são, assim, revisitadas a partir dos procedimentos narrativos de construção e reconstrução, de reconfiguração, de "colocação em intriga" dos próprios atores sociais (Dosse, 1995: 418).

No campo do estudo das representações sociais e/ou coletivas, esse movimento correspondeu a um retorno à noção de sujeito (Jodelet, 2009; 2017). Isso leva a uma mudança na abordagem de fenômenos representativos que os coloca na interseção de três esferas de pertencimento: a esfera subjetiva, a esfera intersubjetiva, a esfera trans-subjetiva. Este modelo pressupõe que o entrelaçamento entre elementos do privado, do social e do coletivo não corresponde a um simples amálgama, mas a uma estratificação. Isso leva a pensar uma organização do sistema de representação de um determinado objeto como uma série de estratos, alguns dos quais - atravessando o conjunto do corpo social, como a ideologia, os modelos culturais, ou aqueles transmitidos pela comunicação social, em particular as mídias - apresentam um caráter mais estável e servem como suporte de inferência para produções situadas em um tempo e em um espaço definidos por sujeitos inscritos em um contexto em que entra em jogo as imposições de seu pertencimento social e cultural, e os aportes de suas interações com o que está ao seu redor. Neste caso, teríamos que lidar com vários tipos de representação, sendo que alguns dentre eles são referentes estáveis, a partir dos quais podem ser feitas inferências e representações de objetos contextualizados. Estas últimas são suscetíveis a mudanças de acordo com as estruturas e condições de vida ou épocas, o pertencimento social e cultural dos sujeitos. Importa observar que, em qualquer caso, as representações permitem expressar a identidade dos sujeitos. Considerar 
a subjetividade e suas relações com as formas de participação social conduz a uma exploração de novas dimensões da produção representativa, especialmente a do imaginário que se desenvolve no contexto da globalização, para a análise a partir da qual recorrer às representações torna-se necessário.

\section{Representações em \\ um espaço globalizado}

A globalização recebe diversas definições e se aplica a diferentes setores da vida humana (Held \& Mcgrew, 2007). Ao debatê-la, deve-se lembrar de duas considerações que, cada uma à sua maneira, remetem à pertinência da abordagem em termos de representação social: o hibridismo dos fenômenos e o questionamento identitário que implica a globalização.

De fato, os estudos sobre a globalização abordam o hibridismo cultural e o pluralismo de significados que circulam em situações locais. Isso cria um campo de aplicabilidade para as representações sociais, que podemos considerar como fenômenos híbridos, associando diferentes tipos de saber e cuja teoria desenvolve os processos de seu entrelaçamento. A representações se constroem a partir de dois processos: a ancoragem, que permite a assimilação da novidade no sistema de pensamento existente; e a objetivação, acolhendo a novidade para integrá-la nas estruturas da ação cotidiana. A polifasia cognitiva explica as possibilidades de coexistência entre formas de pensar pertencentes a universos diferentes e aparentemente incompatíveis.

O hibridismo pode ser tanto uma fonte de submissão como de resistência, quando se leva em consideração a relação entre uma cultura dominante veiculada pela globalização e pelas culturas locais situadas na periferia do processo de globalização. Alguns autores alertam para o fato de que ela pode induzir uma assimilação passiva, reforçando a hegemonia do centro sobre a periferia. Outros evidenciam a força subversiva que tem o empréstimo cultural que

não para de esfumaçar os códigos e os cânones de uma configuração cultural que se desejaria abrangente, mas que é, de certa forma, corroída de dentro para fora, como consequência de seu próprio expansionismo (Abelès, 2008).

Por fim, outros destacam a capacidade de resistência dos movimentos locais. Em todos os casos, aparece a importância do jogo de identidades sustentado pelas representações e pelo imaginário. Usarei dois exemplos para ilustrar esta constatação. 
Ao analisar a sociedade em redes, baseando-se nos meios de comunicação, em seu livro The power of identity, Castells (1997) mostra que a resistência à globalização leva ao surgimento de poderosas manifestações de identidades coletivas, uma fonte de sentidos para e pelos próprios atores sociais. Estes movimentos sociais atuam em nome da singularidade cultural e do direito dos indivíduos de exercerem um controle sobre suas vidas e seu ambiente. Observamos três formas de identidade em oposição mútua. Identidades legitimadoras e defensivas, usadas por movimentos regressivos que resistem à mudança em nome de Deus, da nação, da etnia, da família, do território. Identidades resistentes, que os atores desvalorizados ou estigmatizados pela lógica dominante usam para se proteger, opondo suas raízes sociais e culturais aos princípios e valores das instituições dominantes. Identidades projetos, promovidas por agrupamentos inovadores com a ambição de mudar as relações humanas.

No final de sua análise, Castells diz que doravante "o poder reside nas mentes". Difundido por redes globais, ele se encontra em códigos, em informações, em imagens e em representações em torno dos quais as sociedades organizam suas instituições, e os indivíduos seus comportamentos e suas vidas. Não poderíamos ter evidenciado de forma melhor a importância do papel assumido pelas "produções sociais mentais" - para usar uma expressão de Durkheim - que são as representações sociais na nova ordem mundial.

Já Appadurai (1996) refere-se às representações para falar das identidades, e se interessa particularmente pelas culturas das diásporas intercontinentais resultantes da intensificação das migrações e dos deslocamentos profissionais ou turísticos. 0 autor recomenda orientar-se em direção a uma "antropologia das representações" que, tendo em conta a incidência da cultura mediática, dá um papel decisivo ao imaginário, dimensão importante das representações sociais. O papel da imaginação na vida social resulta da mudança da ordem cultural global criada pelo cinema, pela televisão e pelas tecnologias visuais. Ao focar a dinâmica cultural da desterritorialização, um novo estilo de etnografia deveria estudar "o impacto da desterritorialização sobre os recursos imaginativos das experiências vividas localmente". Essa etnografia deve ser um estudo das representações que revela como as possibilidades imaginárias de vida oferecidas em larga escala exercem um poder sobre as trajetórias de vida específicas. Os indivíduos seriam direcionados pelas objetivações de modelos disseminados pela mídia e por eles apropriados, em outras palavras, as representações sociais.

Encontramos, nos vários pensadores da globalização, um eco das problemáticas formuladas no campo de estudo das representações sociais e/ou coletivas. Isso po- 
deria contribuir para o desenvolvimento de uma perspectiva cosmopolita, a permitir o estudo das produções mentais sociais em várias escalas e em vários espaços culturais. Um movimento nesse sentido já foi iniciado na psicologia social, quando pesquisadores da América Latina encontraram no estudo de representações sociais uma forma fecunda de identificar o jogo da cultura e suas especificidades históricas, regionais, institucionais, organizacionais, locais, sem cair em um particularismo que dificulta o intercâmbio e a cooperação.

A partir de então segue uma série de características epistemológicas e metodológicas relacionadas a uma relação crítica e inovadora mantida por pesquisadores latino-americanos com os paradigmas e as problemáticas teóricas advindas de áreas científicas externas:

- A luta contra os danos de uma importação de modelos e de técnicas desenvolvidos nos círculos dominantes do Primeiro Mundo (entre outros: inadequação às questões psicossociais colocadas por situações históricas e contextos locais; atividade científica de pura replicação passiva; não pertinência dos critérios de avaliação da pesquisa). Essa importação foi realizada seja de modo "colonial", entendida no duplo sentido definido por Sendoval (2000), de imperialismo científico do estrangeiro e de mentalidade colonizada, abordando de maneira não crítica o que vem do exterior, seja sob a forma de um modismo que leva a aferrar-se a escolas de pensamento, aparentando como moderno ou novo.

口 A invenção de novas técnicas de aproximação e de intervenção nas comunidades, que impulsionou a psicologia comunitária na América Latina.

口 A criatividade intelectual que, no ponto de encontro entre diversas correntes de pensamento e diversas disciplinas, se abastece de uma história comum e da consideração das especificidades sociais e culturais.

É desejável que esse exemplo tenha sentido para os sociólogos que, esperemos, possam tirar dessa apresentação informações úteis senão convincentes. 


\section{Referências}

ABELÈS, M. Anthropologie de la globalisation. Paris: Payot, 2008.

ALMEIDA, A. M. O.; JODELET, D. (Eds.). Interdisciplinaridade e diversidade de paradigmas. Brasília: Thesaurus, 2009.

AMBOISE, B.; CHAUVIRÉ, C. (Eds.). Le mental et le social. Paris: Éditions de l'École des Hautes Études en Sciences Sociales, 2013.

APPADURAI, A. Modernity at large. Cultural dimensions of globalization. Minneapolis (MN): University of Minnesota Press, 1996.

BENVENISTE, E. Problèmes de linguistique générale. Paris: Gallimard, 1974.

BOURDIEU, P. Ce que parler veut dire. L'économie des échanges symboliques. Paris: Fayard, 1982.

CASTELLS, Manuel. The power of identity, the information age: economy, society and culture. Oxford (UK): Blackwell, 1997.

CHARTIER, R. Le monde comme représentation. Annales, Économies, Sociétés, Civilisations. v. 6, p. 1505-1520, 1989.

CORBIN, A.; COURTINE, J. J.; VIGARELLO, G. Histoire du corps. Paris: Les Éditions du Seuil, 2005.

DARDOT, P.; LAVAL, C. Commun. Essai sur la révolution au XXlème siècle. Paris: La Découverte, 2014.

DE LAGASNERIE, G. Penser dans un monde mauvais. Paris: Presses Universitaires de France, 2017.

DESCOLA, P. Au delà de nature et culture. Paris: Gallimard, 2006.

DOSSE, F. L'empire du sens. L'humanisation des sciences sociales. Paris: La Découverte, 1995.

DUBY, G. Histoire des mentalités. In: SAMARAN, C. (Ed.). L'histoire et ses méthodes, p. 942-945. Paris: Gallimard, 1986.

DURKHEIM, É. Représentations individuelles et représentations collectives. In: DURKHEIM, É. Sociologie et philosophie. Paris: Presses Universitaires de France, 1967 [1898].

FAYE, J. P. La critique du langage et son économie. Paris: Galilée, 1973. 
HELD, D.; MCGREW, A. Globalization theory: approaches and controversies. Cambridge (UK): Cambridge University Press, 2007.

JODELET, D. Representações sociais e mundos de vida. Curitiba (PR): Pucpres; Fundação Carlos Chagas, 2017 [2015].

. A representação: noção transversal, ferramenta da transdisciplinaridade. Cuadernos de Pesquisa. Fundação Carlos Chagas, v. 46, n. 162, p. 1258-1271, 2016.

- Problemáticas psicosociais da abordagem da noção de sujeito. Cuadernos de Pesquisa. Fundação Carlos Chagas, v. 45, n. 156, p. 514-527, 2015.

—. Loucuras e representações sociais. Petrópolis: Vozes, 2005 [1989].

- As representações sociais. Rio de Janeiro: Editora Universidade Estadual do Rio de Janeiro, 2001 [1989].

LAUGIER, S. Le sujet et le public. In: AMBOISE, B.; CHAUVIRÉ, C. (Eds.). Le mental et le social, p. 313-330. Paris: Éditions de l'École des Hautes Études en Sciences Sociales, 2013.

LEPETIT, B. Les formes de l'expérience, une autre histoire sociale. Paris: Albin Michel, 1995.

MORAZÉ, C. La logique dans l'histoire. In: FERRO, M. (Ed.). Savoir et mémoire. "Collection d'entretiens". Abbeville (FR): Imprimerie Paillard, 1994.

MORIN, E. Sur l'interdisciplinarité. "Carrefour des sciences", Colloque Interdisciplinarité. Paris: Editions du CNRS, 1990.

MOSCOVICI, S. Le scandale de la pensée sociale. Paris: Éditions de l'École des Hautes Études en Sciences Sociales, 2013.

Des représentations collectives aux représentations sociales. In: JODELET, D. (Ed.). Les représentations sociales, p. 62-86. Paris: Presses Universitaires de France, 1989.

- La psychanalyse, son image et son public. Paris: Presses Universitaires de France, 1974 [1961].

NOIRIEL, G. Pour une approche subjectiviste du social. Annales, Économies, Sociétés, Civilisations, v. 6, p. 1435-1459, 1989.

OLIVIER DE SARDAN, J. P. La politique du terrain. Sur la production desdonnées en anthropologie. Enquête, v. 1, p. 71-109, 1995. 
RANCIÈRE, J. Le partage du sensible. Esthétique et politique. Paris: La Fabrique, 2012.

RIOUX, J. P.; SIRINELLI, J. F. (Eds.). Pour une histoire culturelle. Paris: Les Éditions du Seuil, 1997.

SENDOVAL, S. O que há de novo na psicologia social latino-americana. In: CAMPOS, R. H.; GUARESCHI, P. (Eds.). Paradigmas em psicologia social, p. 101-109. Petrópolis: Vozes, 2000.

STEINER, P. Les sociologues et les formes de la connaissance. In: WALLISER, B. (Ed.). La distinction des savoirs, p. 251-274. Paris: Éditions de l'École des Hautes Études en Sciences Sociales, 2015.

TOURAINE, A. Penser autrement. Paris: Fayard, 2007.

VYGOTSKY, L. S. Le problème de la conscience dans la psychologie du comportement. Société française, v. 50, p. 35-47, 1984.

WALLISER, B. La distinction des savoirs. Paris: Éditions de l'École des Hautes Études en Sciences Sociales, 2015.

WIEVIORKA, M. Introduction. In: WIEVIORKA, M.; DEBARLE, A.; OHANA, J. (Eds.). Les sciences humaines en mutation, p. 9-21. Paris: Éditions de la Maison des Sciences de l'Homme, 2007.

WINDISCH, U. Pensée sociale, langage en usage et logiques autres. Lausanne (CH): L'Âge d'Homme, 1982. 